\title{
Assessment of the effect of aerotechnogenic pollution on male reproductive organs Convolvulus arvensis $\mathrm{L}$.
}

\author{
Evelina Ibragimova* and Olga Manankova \\ Crimean Engineering and Pedagogical University named after Fevzi Yakubov, Department of \\ Biology, Ecology and Life Safety, 295015, Simferopol, Russia
}

\begin{abstract}
The article presents the results of assessing the impact of airtechnogenic pollution on the male generative organs of Convolvulus arvensis L. The unfavorable effect of toxic emissions from the landfill of municipal solid waste and vehicles on the processes of microsporogenesis of the populations of Convolvulus arvensis L., which was expressed in the production of large abortive pollen, was established. It is recommended to use the male generative system of the populations of Convolvulus arvensis L. for bioindication of the quality of the state of the environment.
\end{abstract}

\section{Relevance of research}

In the XXI century, there has been a transition of the biosphere and society to a new stage of its development - the technosphere, a distinctive feature of which is the technogenic human activity, which has a negative impact on the natural environment. The destruction of natural ecosystems is noted, accompanied by the emergence of crisis situations of a global nature, leading to climate change on the planet and the contamination of terrestrial space. Statistical studies show that $99-98 \%$ of the used natural resource of the planet goes to waste that is not assimilated by nature, and only $1-2 \%$ remains in the final product $[1,2]$. The appearance of a huge amount of waste, often in the form of substances unusual for nature, led to a crisis of reducers, the essence of which is their inability to cleanse the biosphere from pollution, leading to a disruption of the cycle of substances in the biosphere [1] and an excess of the reducing human activity over the producing activity of the biosphere [3 ].

Technogenic chemical pollution of the environment has an adverse effect on phytocenoses [4]. Therefore, first of all, it is necessary to study the influence of man-made human activity on the first link of the trophic chain - photoautotrophic plants.

The existing test systems make it possible to assess the mutagenic activity of many environmental pollutants, as well as to predict the genetic consequences of environmental pollution. However, it is advisable, along with the traditional methods of accounting for mutations, to use indirect indicators of the mutagenic effect of various pollutants. These methods include a test for determining the sterility of pollen from various plants, since it

\footnotetext{
* Corresponding author: evelina_biol@mail.ru
} 
has been established that the maximum amount of pollen with developmental defects was found in areas with the worst environmental conditions [5, 6].

In recent years, in the Crimean region, there has been a progressive increase in anthropogenic load on environmental objects and, as a consequence, the deterioration of the ecological situation. The main sources of environmental pollution in Crimea are emissions from vehicles, as well as landfills for solid household waste. In recent years, a large amount of solid household waste has accumulated on the territory of the region in the form of authorized and unauthorized garbage dumps [7]. High morbidity of the population is registered, degradation of the plant component of the ecosystem is noted [8,9], one of the reasons for which may be soil pollution [10], atmospheric air associated with the neighborhood of the city dump. The problem of the landfill for household waste is aggravated by the regular burning of garbage, accompanied not only by air pollution, but also by chemical processes occurring in the layers of garbage, in which the concentration of poisons formed by landfills increases hundreds of times [7].

The purpose of this study was to assess the effect of emissions from the landfill of solid household waste and vehicles on the morphometric parameters and sterility of pollen from populations of wild plants. Populations of Convolvulus arvensis L. were selected as the object of the study, since the population is an indicator of the state of the environment [11].

\section{Materials and methods}

The material for the research was male generative organs collected from wild plants growing around the solid waste landfill in Simferopol (I), as well as growing along roads with a high traffic load (II). The control variant (C) was the generative organs of plants growing in ecologically favorable conditions of Simferopol.

The material collected from these biotopes was fixed in acetic acid alcohol (3: 1), and then, after washing in $70 \%$ alcohol, was transferred into $80 \%$ ethyl alcohol, where it was stored until cytological analysis. The fertility of pollen grains was determined by the acetocarmine method [12]. The study of the morphological structure of pollen grains was carried out using a morphometric image analysis system, which includes a Carl Zeiss microscope, a SunKwang video camera, and a personal computer. Statistical data processing was performed using the Microsoft Excel 2007 software package. The Student's t-test was used as a criterion for assessing the reliability of the observed changes [13].

\section{Results and discussion}

The results of the studies showed that in the populations of Convolvulus arvensis L. the male reproductive organs turned out to be sensitive to the impact of emissions from the landfill of solid domestic waste, as evidenced by the rather high level of sterility of pollen grains (Table 1).

Analysis of the data obtained shows that between wild plants growing in different environmental conditions, there are certain differences in the fertility of the male gametophyte. In particular, the populations of $C$. arvensis L. in the ecologically favorable zone had a rather low spontaneous level of sterility of pollen grains $(2,5 \%)$. In populations growing in biotopes experiencing technogenic pressure, there was a significant increase in the number of abortive pollen grains as compared to the control. In particular, the level of sterility of the male gametophyte $C$. arvensis L., collected from the ecologically unfavorable zone of the city dump, significantly increased by 3,1 ( $p<0,001$ ) times compared with the control variant, in plants growing along roads with heavy traffic -3.2 times ( $p<0,001)$, respectively. Consequently, the fertility of pollen from wild plants is 
inversely proportional to the level of environmental pollution. Apparently, in the studied biotopes, there is an accumulation of ecotoxicants with a gametocidal effect. Our hypothesis is confirmed by the calculation of the average error of the difference [14] for the control and experimental variants of the study, which indicates the unfavorable sanitary and epidemiological state of the biotopes of the city dump and the roadside zone of highways. This necessitates taking special preventive measures to improve the ecological state of the studied biotopes.

Table 1. Sterility of the pollen of Convolvulus arvensis L. in the ecologically clean zone (control) and the area of the solid waste landfill

\begin{tabular}{|c|c|c|c|c|c|c|c|c|}
\hline \multirow[t]{2}{*}{ № } & \multirow[t]{2}{*}{ Biotope } & \multicolumn{3}{|c|}{ Pollen fertility } & \multicolumn{3}{|c|}{ Pollen sterility } & $\mathrm{F} / \mathrm{S}$ \\
\hline & & quantity & $\bar{x} \pm S_{\bar{x}}$ & $\%$ & quantity & $\bar{x} \pm S_{\bar{x}}$ & $\%$ & \\
\hline 1. & $\mathrm{C}$ & 4877 & $12,25 \pm 0,13$ & 97,5 & 123 & $0,31 \pm 0,03$ & 2,5 & 39 \\
\hline 2. & $\mathrm{I}$ & 4610 & $11,03 \pm 0,10^{*}$ & 92,2 & 390 & $0,93 \pm 0,05^{*}$ & 7,8 & 11,8 \\
\hline 3. & II & 5021 & $9,0 \pm 0,11^{*}$ & 92,1 & 401 & $0,85 \pm 0,04^{*}$ & 7,9 & 11,6 \\
\hline
\end{tabular}

Note: C - control, I - solid waste dump, II - roadside zone; * - differences from control are significant at $\mathrm{p}<0,001$.

The calculation of the ratio of fertile to sterile pollen grains (F/S), which characterizes the sensitivity of the reproductive organs of the studied plants for each variant, gave the following results: the ratio of fertile to sterile pollen grains decreased 3,3 (I biotope) and 3,4 times (II biotope ) compared to the control. Thus, analyzing and comparing the indicators of the ratio of fertile and sterile pollen grains in the control and experimental variants, it can be concluded that the male generative system of $C$. arvensis L. turned out to be quite sensitive to airborne industrial pollution of the environment. Our hypothesis is consistent with the literature data indicating the sensitivity of the male generative system of $C$. arvensis L. to the action of technogenic chemical pollutants. In particular, when studying the effect of the effects of background pesticide pollution on the pollen fertility of a number of wild plants, it was found that $C$. arvensis L. is most sensitive to environmental pollutants and can be recommended as an indicator test system for studying the toxicity of industrial pollutants [15].

Figure 1 shows photomicrographs of the male gametophyte of the studied wild plants growing in an ecologically favorable zone and in biotopes with aerotechnogenic pollution of the environment, where an increased production of large abortive pollen grains was found. 

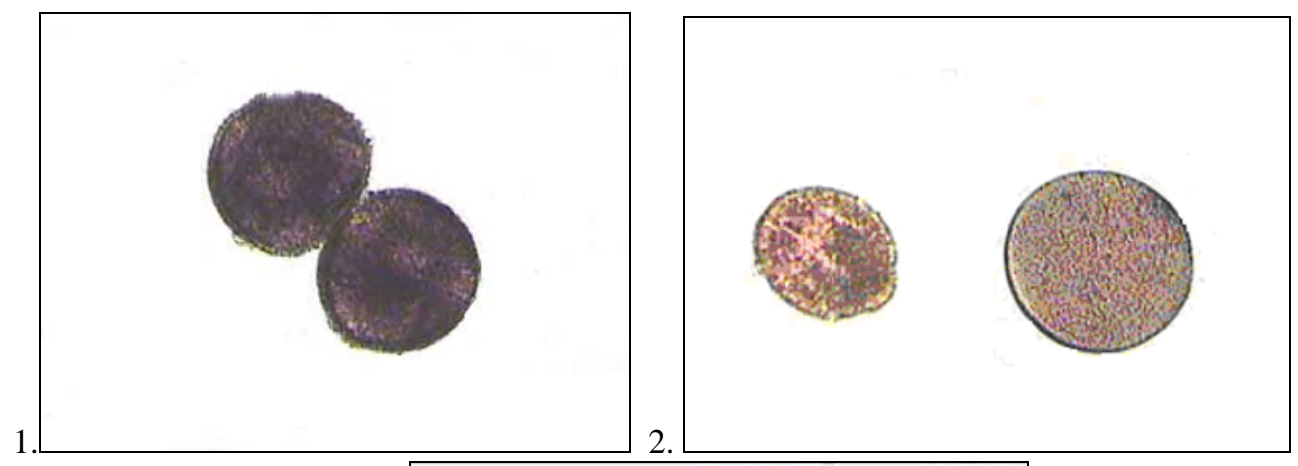

3.

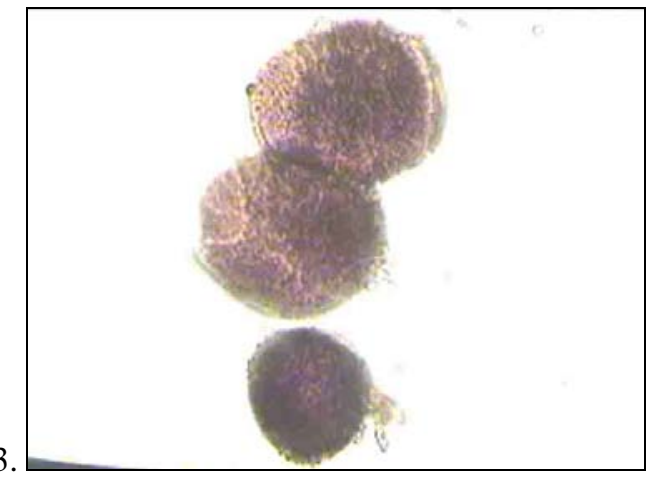

Fig. 1. Male gametophyte Convolvulus arvensis L. (magnification 1,1x16), growing in an ecologically favorable zone (1), dumps of solid domestic waste (2) and in the roadside zone (3).

Morphometric analysis of pollen grains of $C$. arvensis L. showed (Table 2) that the size of the fertile pollen of plants in the control zone slightly exceeded the size of the pollen grains of the ecologically unfavorable zone; however, these changes were statistically insignificant $(p>0,05)$ in the waste and statistically significant $(p<0,001)$ in populations growing along the roads.

Table 2. Morphometric parameters of Convolvulus arvensis L. pollen grains growing in an ecologically favorable zone and biotopes with aerotechnogenic pollution of the environment

\begin{tabular}{|c|c|c|c|c|c|}
\hline \multirow{2}{*}{ № } & \multirow{2}{*}{ Biotope } & \multicolumn{4}{|c|}{ Size of pollen grains, microns } \\
\cline { 3 - 6 } & & \multicolumn{2}{|c|}{ fertile } & \multicolumn{2}{|c|}{ sterile } \\
\cline { 3 - 6 } & & $\bar{x} \pm S_{\bar{x}}$ & $\bar{x} \pm S_{\bar{x}}$ & $\bar{x} \pm S_{\bar{x}}$ & $\bar{x}_{ \pm} \pm S_{\bar{x}}$ \\
\hline 1. & C & $42,91 \pm 0,73$ & $40,60 \pm 0,69$ & $40,93 \pm 0,69$ & $38,19 \pm 0,70$ \\
\hline 2. & I & $41,31 \pm 0,51$ & $39,53 \pm 0,55$ & $45,61 \pm 1,07^{*}$ & $43,25 \pm 1,14^{*}$ \\
\hline 3. & II & $39,22 \pm 0,13^{*}$ & $36,82 \pm 0,22^{*}$ & $48,61 \pm 0,95^{*}$ & $44,53 \pm 1,51^{*}$ \\
\hline
\end{tabular}

Thus, vehicle emissions have an adverse effect on the male gametophyte of $C$. arvensis L. populations, which is reflected in the size of pollen grains. It should be noted that the revealed changes in the morphometric parameters of fertile pollen produced by the organs of the male generative system, manifested in a decrease in its size with an increase in the amount of ecotoxicants in the air, had an inverse relationship in sterile pollen. It was found 
that the sizes of sterile pollen of plants in the studied biotopes had statistically significant differences and increased compared to the control ( $\mathrm{p}<0,001)$. In particular, the study revealed increased production of large abortive pollen. According to some authors, the production of large pollen grains is the result of nondisjunction of microspore tetrads during microsporogenesis. Consequently, the emissions from the solid waste landfill and vehicles have a gametocidal effect and adversely affect the final stages of the microsporogenesis process of Convolvulus arvensis L.

Thus, the male gametophyte Convolvulus arvensis L. is sensitive to airborne industrial pollution and can be recommended as a test system for assessing the quality of the environment.

\section{Conclusions}

1. Environmental pollution by emissions from the solid waste landfill and vehicles has a negative effect on the organs of the male generative system of the Convolvulus arvensis $\mathrm{L}$. populations growing in these biotopes, as evidenced by the increased production of sterile pollen grains compared to the control variant.

2. The unfavorable effect of toxic emissions from the solid waste landfill and vehicles on the processes of microsporogenesis of the populations of Convolvulus arvensis L., which was expressed in the production of large abortive pollen, was established.

3. It is recommended to use the male generative system of the populations of Convolvulus arvensis L. for bioindication of the quality of the state of the environment.

\section{References}

1. I. Shchukin Ecology for university students, 224 p.(2005). (in Russian)

2. A.A. Gorelov Ecology, 236 p. (2000). (in Russian)

3. Y. Odum Ecology: in 2 volumes (1986). (in Russian)

4. K. Tekle, I. Backeus, J. Skoglund, Z. Woldu Nord. J. Bot., Vegetation on hill slopes in southern Wello Ethiopia: Degradation and regeneration, 17, 5, pp. $483-493$ (1998).

5. O.F. Dzyuba 15th. Int. Bot. Congr., Yokogama, Aug. 28-Sept. 3, 1993: Abstr. Yokogama, Pollen gymnosperms teratomorphs as the result of an ecological stress under conditions of a large city, pp. 287, (1993).

6. A.Y. Magulaev, V.T. Gubareva Stavrop. State Univ. Bul., Features of microsporogenesis in creeping wheatgrass in conditions of industrial pollution, 12, pp. 159-163, 173, (1997). (in Russian)

7. N.V. Bagrov, V.A. Bokov Ecology of Crimea. Reference manual, 360 p., (2003). (in Russian)

8. E.E. Ibragimova Culture of the peoples of the Black Sea region, Reproductive processes in wild plants in disturbed urban ecosystems, 67, pp. 17-20, (2005). (in Russian)

9. E.E. Ibragimova, D.E. Emirova I International scientific-practical conference "Advanced scientific developments - 2006", Pollen of Pinus sylvestris L. as an indicator of unfavorable environmental conditions, 6, pp. 43-47, (2006). (in Russian)

10. E.Y. Kuznetsova, N.A. Surova I All-Ukrainian Congress of Ecologists (ECOLOGY2006). Abstracts presented at the International Scientific and Practical Conference in the city of Vinnitsa, October 4-7, 2006. Ecological problems of procurement of medicinal raw materials in the conditions of the Crimea, pp. 139, (2006). (in Russian) 
11. A.M. Fedota, A.N. Kozlov Cytology and Genetics, Study of the level of genetic safety of the urban population, 4, pp. 41-44, (2005). (in Russian)

12. Z.P. Pausheva Workshop on plant cytology, 304 p. (1980). (in Russian)

13. N.A. Plokhinsky Biometrics, 367 p. (1970). (in Russian)

14. A.M. Merkov, L.E. Polyakov Sanitary statistics, 384 p. (1974). (in Russian)

15. F.M. Khalimov Genetic effects of anthropological pollution of the environment in the Zarafshan valley. Collection of scientific papers, Study of the effects of background pollution with pesticides on the fertility of pollen of some plants, pp. 26-32 (1989). (in Russian) 